\title{
Ultra-High-Frequency Left Prefrontal Transcranial Magnetic Stimulation as Augmentation in Severely III Patients with Depression: A Naturalistic Sham-Controlled, Double-Blind, Randomized Trial
}

\author{
Heiko Ullrich ${ }^{a}$ Laura Kranaster $^{b}$ Erich Sigges ${ }^{c}$ Jürgen Andrich ${ }^{d}$ \\ Alexander Sartorius ${ }^{\mathrm{b}}$ \\ ${ }^{a}$ Department of Psychiatry and Psychotherapy, Kreisklinikum Siegen GmbH, Siegen, ${ }^{\text {b }}$ Department of Psychiatry \\ and Psychotherapy, Central Institute of Mental Health, Medical Faculty Mannheim/Heidelberg University, \\ Mannheim, 'Department of Neurology, Evangelical Clinics Gelsenkirchen, Gelsenkirchen, and d Department of \\ Neurology, Klinik Feldberg, Feldberg, Germany
}

\section{Key Words}

Repetitive transcranial magnetic stimulation •

Ultra-high-frequency stimulation • Major depression •

Cognitive function

\begin{abstract}
Background and Aim: Repetitive transcranial magnetic stimulation (rTMS) is supposed to be not as effective in severe depression as it is in medium depression. We evaluated the treatment response to an ultra-high-frequency (UHF; 30 $\mathrm{Hz}$ ) approach, which was used to maximize the rTMS efficacy in severely ill patients. Methods: 43 severely depressed patients were included in the randomized, double-blind study and received either rTMS with $30 \mathrm{~Hz}$ over the left dorsolateral prefrontal cortex or sham condition for 3 weeks as an add-on therapy to stable antidepressant medication. Hamilton Depression Rating Scale (HDRS) and cognitive performance were evaluated before and after the intervention. $\boldsymbol{R e}$ sults: In the active UHF group, the HRDS score was reduced by about 7.2, whereas the sham condition showed a smaller
\end{abstract}

\section{KARGER}

Fax +41613061234

E-Mail karger@karger.ch

www.karger.com
(C) 2012 S. Karger AG, Basel

$0302-282 X / 12 / 0663-0141 \$ 38.00 / 0$

Accessible online at:

www.karger.com/nps reduction of the HDRS score with 3.9. However, lithium as a covariant was responsible for the outcome difference, not the group of stimulation. No adverse events were reported. Comparing the differences of both groups in the pre- and post-study performance in a trail-making test, a group effect for the UHF group that was not influenced by the lithium intake was observed. Conclusion: A 30-Hz left prefrontal rTMS in severely depressed patients was safe and no adverse events occurred. Due to a strong effect of lithium as a covariate, we could not demonstrate favorable antidepressant effects of the UHF stimulation compared to sham. However, we found an improvement of processing speed performance in the UHF group, which covaried with improvement of psychomotor retardation.

Copyright $\odot 2012$ S. Karger AG, Basel

H.U. and L.K. contributed equally to this work. 


\section{Introduction}

Repetitive transcranial magnetic stimulation (rTMS) has transformed from a neurological research tool into a highly promising treatment alternative in psychiatry. Especially in the therapy of major depressive disorder, the noninvasive rTMS has reached considerable attention with milestones like the first clinical trial [1], the approval by the US Food and Drug Administration [2] or the publication of the to date largest multisite study [3] within the last two decades. Alternatives to antidepressants are urgently needed, as about one third of patients will not remit with their first antidepressant challenge and $15 \%$ of the patients with depression are not helped at all by antidepressant medication. Existing data regarding antidepressant efficacy of rTMS are somewhat inclusive, meaning that there are many reports that were able to demonstrate antidepressant effects [3-7], but equally reports that could not show superiority to sham treatment or arguable clinically relevant effects [8-12]. However, the majority of meta-analyses concludes that rTMS is superior to sham in the treatment of depression [13-17]. Most studies agree that the differential influence of intensity, duration, and frequency of rTMS on antidepressive efficacy has not been fully explored so far. rTMS is supposed to be more successful in patients whose degree of depression is rather mild to medium than severe. Unfortunately, in severely depressed patients, treatment resistance is frequent and new options are most valuable especially for this population.

We evaluated the treatment response to an ultra-highfrequency (UHF; $30 \mathrm{~Hz}$ ) approach over the left dorsolateral prefrontal cortex, which was used to maximize the rTMS efficacy in severely ill patients. A $30-\mathrm{Hz}$ stimulation frequency is about $50 \%$ higher than the usual highfrequency stimulation, but considering the large number of subjects and patients who have undergone rTMS studies and the small number of seizures, the risk of rTMS to induce seizures is certainly very low $[18,19]$. Fifty hertz was already used in patients with Parkinson's disease; 30 $\mathrm{Hz}$ is to our knowledge the highest frequency used to analyze antidepressant characteristics in patients with depression. An animal study with a model of depression that compared 20 - and $30-\mathrm{Hz}$ stimulation already suggested that the effectiveness of rTMS may be augmented by increasing the frequency of rTMS impulses [20].

In order to create 'real world' conditions, we used a naturalistic augmentation or add-on study, with patients continuing the antidepressant medication they already took before the study, but that had not led to a response.

\section{Methods}

\section{Patients}

The present study has been carried out in accordance with the Code of Ethics of the World Medical Association (Declaration of Helsinki) and written informed consent was obtained from all participants before inclusion in the study. There were two cohorts ( $\mathrm{n}=26$ and $\mathrm{n}=17$ ) with a total sample of 43 depressed subjects (16 males and 27 females), who were recruited between 2007 and 2009 from the Department of Biological Psychiatry and Neuroscience, Evangelical Clinics Gelsenkirchen, Germany. Inclusion criteria were beneath the present primary diagnosis of at least a moderate depressive episode with a minimum of 20 points on the HDRS without psychotic features (DSM-IV: 296.52, 296.53, $296.32,296.33,296.22$, or 296.23), age from 18 to 75 years and both a certain stability of the course (no relevant change in the week before the start of the study) and stability of antidepressant medication (intake of either venlafaxine or mirtazapine over at least 3 weeks). Exclusion criteria were a history of seizures, moderate to severe head traumas or brain surgery, current other psychiatric disorders, current severe neurological or medical diseases or the implementation of a pacemaker. Before inclusion, internal and neurological examinations and additionally laboratory and EEG were performed.

In order to facilitate a clinical realistic study, all patients received an antidepressant pharmacological standard treatment with either venlafaxine or mirtazapine and additional standard inpatient treatment as usual. Inclusion was possible after at least 3 weeks of stable intake of one of these antidepressants. The allowed concomitant medication was lithium, when already established at least 4 weeks before inclusion, lorazepam up to $1.5 \mathrm{mg} /$ day and antipsychotics. Anticonvulsive mood stabilizers were not allowed throughout the study.

Baseline stability is an important issue regarding minimizing bias through placebo response and naturalistic course; in order to exclude patients who got better without intervention, it was necessary that the HDRS score did not improve over $20 \%$ between 1 week before stimulation and at the day of the first scheduled stimulation. If an improvement over $20 \%$ occurs and the inclusion criteria are still fulfilled, the study intervention is postponed another week. Then baseline stability is checked again, and if there is still an improvement over $20 \%$, the patient is excluded from the study.

\section{Outcome Measures}

The primary endpoint of the study was a clinician-rated measure of depressive symptoms with the HDRS (21-item version). Weekly rating was performed by the psychiatrist on ward, who had daily contact with the patient, but was not involved in the study at all and was not aware of the patient's group (active stimulation or sham), thus resulting in a double-blind condition.

Secondary outcome parameters were the self-reported measure of depressive symptoms using Beck's Depression Inventory (BDI) and performance using three cognitive tests, namely the Zahlen-Verbindungs-Test (ZVT), a cognitive test that included a trail-making test challenging processing speed [21], the SyndromKurztest (SKT), a brief neuropsychological test battery for the assessment of potential deficits in memory and attention [22], and the Mehrfachwahl-Wortschatz-Test Version B, a multiple-choice verbal intelligence test estimating the premorbid intelligence lev- 
el. Another parameter was patient satisfaction with the rTMS treatment measured with a visual analogue scale after the completion of the study.

Evaluation of all outcome parameters took place before the rTMS treatment and after completion of 3 weeks of stimulation. Another outcome parameter was if the patient could be considered as 'responder', which is defined as a reduction of at least $50 \%$ in HDRS score, or as 'remitter', which is defined as an HDRS score $<8$.

\section{rTMS Treatment}

rTMS was administered using a MagPro stimulator (Dantec, Denmark) with a figure-of-eight coil with an outer diameter of 97 $\mathrm{mm}$. Prior to the initial rTMS session, the resting motor threshold was determined as the lowest intensity that could induce an involuntary movement of the abductor pollicis brevis muscle in at least 3 out of 6 times. Stimulation was applied at $110 \%$ of the motor threshold. Coil positioning was determined by the 10-20 EEG system, such that F3 corresponds to the left dorsolateral prefrontal cortex [23]. We chose two different, alternated randomized stimulus conditions. Stimulation was performed for 3 weeks on each workday (total of 15 sessions).

Left-side UHF $(30 \mathrm{~Hz})$ stimulation was applied in 20 trains of 3 -second duration with 57-second intertrain intervals, resulting in 1,800 pulses per session. This condition was regarded as the active treatment with hypothesized antidepressant efficacy.

Left-side low-frequency (LF; $1 \mathrm{~Hz}$ ) stimulation was applied in 11 trains of 90 -second duration with 30 -second intertrain intervals, totalling 990 pulses per session. That condition was regarded as the not active, sham treatment.

\section{Statistical Analysis}

All statistics were performed using STATA ${ }^{\circledR}$ (version 11; StataCorp, Tex., USA) at a significance level of 0.05 , except for the three cognitive tests, where we corrected for multiple testing with Bonferroni correction with a significance level of $0.05 / 3=0.017$. Baseline differences between the two groups were analyzed with the two-tailed paired t tests or, if appropriate, with Pearson's $\chi^{2}$ test. Comparisons of the outcome parameters (HDRS, BDI, ZVT, SKT, Mehrfachwahl-Wortschatz-Test Version B) before and after the rTMS treatment were analyzed with two-tailed paired t tests. Comparisons between the two stimulation groups were carried out with one-way ANOVA, including possible covariates.

\section{Results}

\section{Characteristics of the Study Population}

We could include altogether 43 subjects in two cohorts. Unfortunately, the second cohort $(\mathrm{n}=17)$ lacks information about the intake of lithium, benzodiazepines and antipsychotics during the study. There were no significant baseline differences in the two cohorts. Twentytwo subjects were randomized for the UHF group and 21 subjects for the LF group. No patient was excluded due to insufficient baseline stability. Demographic and baseline clinical information are shown in table 1.

Ultra-High-Frequency rTMS for Severe Depression
Table 1. Demographic data of both groups

\begin{tabular}{lcll}
\hline & UHF (active) & LF (sham) & $\mathrm{p}$ \\
\hline Number & 22 & 21 & \\
Male/female, \% & $31.8 / 68.2$ & $42.9 / 57.1$ & 0.45 \\
Age, years & $56.9 \pm 10.2$ & $54.1 \pm 7.8$ & 0.31 \\
HDRS score before rTMS & $30.4 \pm 4.8$ & $28.2 \pm 3.9$ & 0.12 \\
BDI score before rTMS & $32.0 \pm 11.9$ & $29.0 \pm 9.6$ & 0.37 \\
Stimulus intensity, \% & $43.4 \pm 2.9$ & $43.2 \pm 2.0$ & 0.87 \\
Duration of illness, years & $6.9 \pm 3.4$ & $6.4 \pm 6.0$ & 0.75 \\
Lithium, \% & $31.3(\mathrm{n}=16)$ & $0.0(\mathrm{n}=10)$ & 0.05 \\
Antipsychotics, \% & $81.25(\mathrm{n}=16)$ & $50.0(\mathrm{n}=10)$ & 0.09 \\
Benzodiazepines, \% & $87.50(\mathrm{n}=16)$ & $50.0(\mathrm{n}=10)$ & 0.04
\end{tabular}

Data are presented as means with standard deviation.

In the UHF group, $68.2 \%$ were female and the average age was 56.9 years (SD: 10.2). The baseline HDRS score was 30.4 (SD: 4.8) and the baseline self-rated BDI score was 32.0 (SD: 11.9). In the LF group, $57.1 \%$ were female and the mean age was 54.1 (SD: 7.8). The HDRS mean score before the treatment was 28.2 (3.9) and the BDI mean score was 29.0 (SD: 9.6). The stimulus intensity and the duration of illness did not differ in the two groups [stimulus intensity: UHF, 43.4\% (SD: 2.9) and LF, 43.2\% (SD: 2.0); duration of illness: UHF, 6.9 years (SD: 3.4 ) and LF, 6.4 years (SD: 6.0)]. However, $33.8 \%$ of the patients in the active UHF group were taking lithium during the study, but no patient in the sham LF group did $(p=0.049)$ and benzodiazepine intake was significantly more often observed in the active group [UHF: $87.5 \%$ and LF: 50.0\% $(p=0.04)]$. Antipsychotics were taken during the study by $81.3 \%$ of patients in the UHF group and by $50.0 \%$ of the subjects in the LF group $(\mathrm{p}=0.09)$.

\section{Safety}

Thirty-hertz UHF was well tolerated by the participants. All patients completed the study and no seizure occurred. No adverse events were reported by the patients. In the patient satisfaction of the treatment measured with a visual analogue scale, we found no difference between the two groups $[F(1,41)=0.03, p=0.86$; data not shown].

\section{Clinical Outcome Parameters}

The clinical outcome parameters are presented in table 2 . The primary endpoint of the study was the difference between the baseline HDRS score and the final 
Table 2. Clinical outcome data of both groups

\begin{tabular}{lccl}
\hline & UHF (active) & LF (sham) & $\mathrm{p}$ \\
\hline Final HDRS score & $23.1 \pm 5.7$ & $24.3 \pm 5.7$ & 0.48 \\
HDRS score difference & $7.2 \pm 4.2$ & $3.9 \pm 3.8$ & $0.01^{\mathrm{a}}$ \\
$\quad$ Without lithium & $5.7 \pm 2.3$ & $3.9 \pm 3.8$ & 0.11 \\
HDRS score reduction, \% & 23.9 & 13.8 & - \\
$\quad$ Without lithium & 18.8 & 13.8 & - \\
Final BDI score & $32.0 \pm 11.9$ & $29.0 \pm 9.7$ & 0.60 \\
BDI score difference & $6.3 \pm 6.3$ & $5.3 \pm 7.1$ & 0.62 \\
Remission & 0 & 0 & - \\
Response & $4^{\mathrm{a}}(18.2 \%)$ & 0 & 0.32 \\
\hline
\end{tabular}

Data are presented as means with standard deviation.

a 3 out of 4 patients with response in the active treatment group were taking lithium during the study.

Table 3. Outcome of the cognitive tests in both groups

\begin{tabular}{lrrl}
\hline & UHF (active) & LF (sham) & \multicolumn{1}{c}{$\mathrm{p}$} \\
\hline ZVT & & & \\
$\quad$ Baseline & $166 \pm 64.5$ & $139.1 \pm 47.8$ & n.s. \\
$\quad$ Final & $145.4 \pm 60.4$ & $131.7 \pm 48.8$ & n.s. \\
$\quad$ Difference & $20.6 \pm 16.7$ & $2.1 \pm 27.4$ & 0.010 \\
SKT & & & \\
$\quad$ Baseline & $7.6 \pm 5.7$ & $4.9 \pm 3.3$ & - \\
$\quad$ Final & $4.9 \pm 5.5$ & $3.8 \pm 3.8$ & - \\
$\quad$ Difference & $2.5 \pm 2.3$ & $1.3 \pm 1.6$ & 0.064 \\
Mehrfachwahl- & & & \\
Wortschatz-Test & & & \\
Version B & & $34.6 \pm 2.1$ & - \\
$\quad$ Baseline & $31.4 \pm 2.1$ & $2.8 \pm 4.7$ & 0.385 \\
$\quad$ Final & $35.3 \pm 2.6$ & $37.4 \pm 2.7$ & - \\
$\quad$ Difference & $3.9 \pm 3.8$ & $2.8 \pm 4$ & \\
\hline
\end{tabular}

Data are presented as means with standard deviation. n.s. = Not significant.

HDRS score after the study. The final HDRS score after 3 weeks of add-on rTMS was 23.1 (SD: 5.7; range: 12-34) in the active group and 24.3 (SD: 5.7; range: $11-35$ ) in the sham group. Both groups showed an improvement of symptoms measured by the HDRS; the active, UHF group showed an average reduction of the HDRS score of 7.2 (SD: 4.2 ; range: $2-17, \mathrm{p}<0.001$ ), whereas the sham condition, LF group showed a significantly smaller reduction of the HDRS score of 3.9 (SD: 3.8 ; range: $0-13$, p < 0.001) $[\mathrm{F}(1,41)=7.5, \mathrm{p}=0.009]$. However, lithium as a covariant, which was unequally distributed between the two groups despite randomization, was responsible for the difference in outcome $[\mathrm{F}(1,23)=13.8, \mathrm{p}=0.001]$, but not the group of stimulation $[\mathrm{F}(1,23)=0.3, \mathrm{p}=0.58]$. Other covariates such as sex, age, antipsychotic or benzodiazepine intake had no significant influence on the results.

Due to the strong lithium influence, the HDRS score between the patients who took lithium $[\mathrm{n}=5$; HDRS score difference: $12.6(4.7)]$ and those who did not $[\mathrm{n}=11$; HDRS score difference: 6 (2.3)] within the UHF group was compared and a statistically significant difference was found $[\mathrm{F}(1,15)=14.85, \mathrm{p}=0.0018]$.

In a subgroup analysis, patients were divided into two groups: very severely depressed with an HDRS score $\geq 30$ [n $=21$, HDRS score: 33.0 (SD: 2.5)] and severely depressed patients with an HDRS score $<30[\mathrm{n}=22$, HDSR score: 25.9 (SD: 2.8)]. In both subgroups, we found no superiority of UHF compared to LF stimulation [severely depressed patients: $F(1,20)=2.55, p=0.13$ and very severely depressed patients: $\mathrm{F}(1,10)=0.2, \mathrm{p}=0.66)$ ], when considering the lithium covariate.

The difference between baseline and final BDI score showed an amelioration of self-perceived depressive symptoms over the study in both groups [UHF: 6.3 (SD: 6.3), p < 0.001; LF: 5.3 (SD: 7.1), $\mathrm{p}=0.003$ ]. However, there were no differences between the active and the sham group $[\mathrm{F}(1,41)=0.26, \mathrm{p}=0.62]$. There were no patients in both groups who reached the state of remission after the study. Four patients reached the criteria defined as response; all were in the UHF group, and 3 of them were taking lithium.

\section{Cognitive Parameters}

The cognitive parameters are summarized in table 3. While the sham (LF) group showed no difference in the pre- and post-study performance in the ZVT (2.1; SD: $27.4, p=0.21$ ), the active group showed a significant improvement of the cognitive performance in this test (20.6; SD: 16.7, $\mathrm{p}<0.0001)$. Comparing the differences of both groups, we found a clear-cut group effect for the UHF group $[F(1,41)=7.2, p=0.010]$ that was not influenced in a significant manner by the lithium intake and was significant even after correction for multiple testing.

In the SKT, we found an improvement of test performance in the post-study test compared to the baseline test before the stimulation in both groups [UHF: 2.5, SD: 2.3, $\mathrm{p}<0.001$; LF: 1.3 (SD: 1.6), $\mathrm{p}=0.008$ ], but no significant group difference $[\mathrm{F}(1,41)=3.6, \mathrm{p}=0.06]$.

Similar to the SKT, in the Mehrfachwahl-WortschatzTest Version B, we found an improvement over time in both groups [UHF: 3.9 (SD: 3.8), p < 0.001; LF: 2.8 (SD: 
$4.7), \mathrm{p}=0.015]$, but no group difference $[\mathrm{F}(1,41)=0.77$, $\mathrm{p}=0.39]$.

As we could show a stable group difference in the ZVT, a trail-making test, but not in the other cognitive tests, we assumed that the unique component of the ZVT is processing speed. We hypothesized, that rTMS might lead to an amelioration of psychomotor retardation measured by the change of item 8 in the HDRS. Thus we found a significant influence of the covariate 'psychomotor retardation' on the performance in the ZVT $[\mathrm{F}(2,24)=4.54$, $p=0.044]$. However, the effect was not strong enough to produce a group difference of the improvement of psychomotor retardation measured by the change of item 8 of the HDRS $[\mathrm{F}(1,31)=0.04, \mathrm{p}=0.84]$.

\section{Discussion}

In this randomized, double-blind trial, the patients received 3 weeks of rTMS treatment additionally to a concurrent stable antidepressant medication that alone did not lead to a significant antidepressant response. UHF stimulation at the left dorsolateral prefrontal cortex was considered as the active treatment, whereas left LF stimulation was considered as the nonactive, sham treatment.

In this rTMS study, we present two innovations: we recruited a sample of the most severely depressed patients with a baseline HDRS score (21-item version) of about 30 in the active treatment group. In the literature, an HDRS score of at least 25 is already considered as severely depressed $[24,25]$. To our knowledge, no published randomized rTMS study with depressed patients had a higher HDRS baseline score. Because there are doubts about the potency of rTMS in such a severely depressed sample $[26,27]$, we wanted to provide maximum power of the rTMS method by raising the stimulus frequency up to 30 $\mathrm{Hz}$, which we consider as UHF. In an animal model of depression, the forced swim test, different frequencies were tested for their antidepressant effects. All tested frequencies $(1-25 \mathrm{~Hz})$ showed antidepressant efficacy comparable with the potency of imipramine. The findings suggest that the antidepressant effect of the higher frequencies is likely to be sustained [28]. To our knowledge, in the already published, randomized studies, frequencies up to $20 \mathrm{~Hz}$ were used, thus our approach is $50 \%$ higher than the already quite established paradigms. Safety data already exist for the $50-\mathrm{Hz}$ stimulation approach from a study with patients suffering from Parkinson's disease [29].

Ultra-High-Frequency rTMS for Severe Depression
In both groups, the patients showed an improvement over the 3 weeks of the study phase, but the difference between UHF and LF was based on the lithium effect or on the combination of lithium and rTMS, but not on a superior stimulation frequency. Unfortunately, there were $31.3 \%$ of patients in the UHF groups who were taking lithium, and no patient in the LF group. Especially the lithium patients showed a good response that resulted in a detectable group effect. Improvement in terms of HDRS score reduction in both groups was in the range of previous studies; however, only $18.2 \%$ in the UHF group showed a response to treatment - and only $4.6 \%$ without lithium intake. This is considerably less than compared to other studies with not so severely depressed patients $[3,30]$.

In spite of randomization, unequal distribution of important variants is a not uncommon problem in small sample studies. However, there are several other reasons why identification of a group difference failed. We designed this study as an add-on study in order to provide more naturalistic data, but in add-on trials, it is known that the sham response is higher than in studies without concomitant antidepressant medication and sham response is known to be considerably large [31]. In fact, with a similar add-on design, a multicenter study with $127 \mathrm{pa}-$ tients investigating antidepressant efficacy failed to demonstrate beneficial results [32]. However, other add-on studies with patients who were also severely depressed could demonstrate superiority of active treatment over sham treatment, with 5 and $10 \mathrm{~Hz}$, respectively $[6,33,34]$.

Secondly, the sham group showed HDRS and BDI score improvement over the study time, which could be a placebo response or the natural course of patients, whose depressive symptoms were severe but who were not considered treatment-resistant as per definition [35]. The sham group got left LF stimulation, thus making it very difficult for the participants to figure out, which treatment they received. That is why we can assume that participants showed full placebo response of this kind of suggestive method, which might make it even more difficult to detect possible existing group differences. Some authors share the opinion that nonpharmacological interventions might produce a greater placebo response than pharmacological ones [36], but others state that placebo rates decrease with severity of depression [37, 38]. Furthermore, it cannot be ruled out that our sham condition also demonstrated some antidepressant effect, as LF rTMS also has an effect in the regional cerebral flow [39]. However, choosing a sham condition is a trade-off between effective blinding and truly inactive 'stimulation'

Neuropsychobiology 2012;66:141-148 
[40]. At least from a clinical point of view, our sham approach did not reveal any relevant effects. No patient from the sham group worsened and the response in the sham group with a mean score reduction of 3.9 in the HRDS was within the reported limits of other groups [3, 33].

Another possible explanation for the negative finding is that the study duration of 3 weeks was simply not long enough to develop a group difference without the lithium covariant. Longer treatment duration seems to be better in terms of antidepressant efficacy $[41,42]$ and two other studies with very severely depressed patients who had a baseline HDRS score of about 30 and a positive finding treated the patients between 4 and 6 weeks $[2,33]$. That is supported by our finding that the cognitive performance in one test (ZVT, trail-making test character) improved considerably in the active treatment group independent from an antidepressant effect of rTMS, while it did not in the sham group. In this test, processing speed was involved, which is known to be considerably disturbed in major depression [43], but was no major compound in the two other psychological tests, in which no group difference occurred. Improved performance in trial-making tests could point towards an amelioration of frontal lobe deficits, which might be an effect of the UHF stimulation. rTMS has already shown to improve cognitive function in Alzheimer's disease [44]. Additionally, rTMS might specifically target psychomotor retardation as a core symptom of depression, thus resulting in fast and better performance in speed processing tasks, which are valid measurements for psychomotor retardation $[45,46]$. Two studies already reported that despite a lack of efficacy in terms of HDRS score reduction, high-frequency rTMS (10 and $20 \mathrm{~Hz}$, respectively) significantly decreased scores on the psychomotor retardation scales [10,47], whereas another study did not find such associations. In our study, we found a significant influence of the covariate 'psychomotor retardation' (quantified by HRDS item 8) on the performance in the trail-making test, thus pointing towards the fact that reduction in psychomotor retardation might be an early step of antidepressant response, similar to some antidepressants.

Another finding worth mentioning is that in the active UHF group, the patients who took lithium had a higher HDRS score reduction than those patients who did not take lithium. This was not necessarily expected, because patients taking lithium were only included in the study, if lithium had already been given for at least 4 weeks before the start of the stimulation. Although very preliminary, our finding might suggest that lithium is a favorable concomitant medication in rTMS and that the combination might facilitate more effects than lithium or rTMS alone.

Limitations of the study are the unequal distribution of lithium intake, which in combination with the modest sample size unfortunately limits the informative value. Another problem of the study is the additional intake of benzodiazepines and antipsychotics, which was either unequally distributed or the information about the intake was missing. In studies investigating antidepressant effects, the use of these two groups of drugs is problematic, because both are known to be able to improve sleep and anxiety, without having clear-cut antidepressant effects, perhaps with quetiapine as an exception. Therefore, antipsychotics might reduce the HDRS score with its three sleep-related items, without unique antidepressant effects.

In summary, $30-\mathrm{Hz}$ left prefrontal rTMS in severely depressed patients was safe and no adverse events occurred. Due to unequal distribution of lithium, we were not able to demonstrate an antidepressant group difference compared to sham. However, we found an improvement of processing speed performance in the stimulation group, which covaried with the improvement of psychomotor retardation. Treating severely depressed patients with rTMS could not be discarded based on our data, especially when bearing in mind that even a mild or modest amelioration, which rTMS could deliver in combination with antidepressants, might have a relevant clinical effect in terms of suicidal prevention or regaining the ability for psychotherapeutic work.

Future clinical research in rTMS for affective disorders has to deal with many aspects. Studying the impact of stimulation parameters (e.g. frequency or intensity) on the efficacy in order to optimize rTMS treatment [48] is definitively one of them, and exploring favorable concomitant medication is another one. Alternative approaches that have been developed in the last few years, and might contain even more potential than the 'conventional' rTMS method, are important and promising research issues, too. Theta burst stimulation is one of them and involves the repetitive application of very short trains at high frequency $(50 \mathrm{~Hz})$ and very short intertrain intervals [49], which is therefore still different from our approach. Preliminary data suggest that theta burst stimulation is a safe method [50] and may have antidepressant effects $[51,52]$. 


\section{References}

1 Pascual-Leone A, Rubio B, Pallardo F, Catala MD: Rapid-rate transcranial magnetic stimulation of left dorsolateral prefrontal cortex in drug-resistant depression. Lancet 1996;348:233-237.

-2 O'Reardon JP, Solvason HB, Janicak PG, Sampson S, Isenberg KE, Nahas Z, McDonald WM, Avery D, Fitzgerald PB, Loo C, Demitrack MA, George MS, Sackeim HA: Efficacy and safety of transcranial magnetic stimulation in the acute treatment of major depression: a multisite randomized controlled trial. Biol Psychiatry 2007;62:1208-1216.

$\checkmark 3$ George MS, Lisanby SH, Avery D, McDonald WM, Durkalski V, Pavlicova M, Anderson B, Nahas Z, Bulow P, Zarkowski P, Holtzheimer PE 3rd, Schwartz T, Sackeim HA: Daily left prefrontal transcranial magnetic stimulation therapy for major depressive disorder: a sham-controlled randomized trial. Arch Gen Psychiatry 2010;67:507-516.

$\checkmark 4$ Eschweiler GW, Wegerer C, Schlotter W, Spandl C, Stevens A, Bartels M, Buchkremer G: Left prefrontal activation predicts therapeutic effects of repetitive transcranial magnetic stimulation (rTMS) in major depression. Psychiatry Res 2000;99:161-172.

5 Jorge RE, Robinson RG, Tateno A, Narushima K, Acion L, Moser D, Arndt S, Chemerinski E: Repetitive transcranial magnetic stimulation as treatment of poststroke depression: a preliminary study. Biol Psychiatry 2004;55:398-405.

$\checkmark 6$ Rumi DO, Gattaz WF, Rigonatti SP, Rosa MA, Fregni F, Rosa MO, Mansur C, Myczkowski ML, Moreno RA, Marcolin MA: Transcranial magnetic stimulation accelerates the antidepressant effect of amitriptyline in severe depression: a double-blind placebo-controlled study. Biol Psychiatry 2005; 57:162-166.

$>7$ Rossini D, Lucca A, Zanardi R, Magri L, Smeraldi E: Transcranial magnetic stimulation in treatment-resistant depressed patients: a double-blind, placebo-controlled trial. Psychiatry Res 2005;137:1-10.

$>8$ Nahas Z, Kozel FA, Li X, Anderson B, George MS: Left prefrontal transcranial magnetic stimulation (TMS) treatment of depression in bipolar affective disorder: a pilot study of acute safety and efficacy. Bipolar Disord 2003;5:40-47.

$>9$ Loo C, Mitchell P, Sachdev P, McDarmont B, Parker G, Gandevia S: Double-blind controlled investigation of transcranial magnetic stimulation for the treatment of resistant major depression. Am J Psychiatry 1999;156: 946-948.

$\checkmark 10$ Hoppner J, Schulz M, Irmisch G, Mau R, Schlafke D, Richter J: Antidepressant efficacy of two different rTMS procedures. High frequency over left versus low frequency over right prefrontal cortex compared with sham stimulation. Eur Arch Psychiatry Clin Neurosci 2003;253:103-109.
11 Poulet E, Brunelin J, Boeuve C, Lerond J, D'Amato T, Dalery J, Saoud M: Repetitive transcranial magnetic stimulation does not potentiate antidepressant treatment. Eur Psychiatry 2004;19:382-383.

12 Miniussi C, Bonato C, Bignotti S, Gazzoli A, Gennarelli M, Pasqualetti P, Tura GB, Ventriglia M, Rossini PM: Repetitive transcranial magnetic stimulation (rTMS) at high and low frequency: an efficacious therapy for major drug-resistant depression? Clin Neurophysiol 2005;116:1062-1071.

13 Schutter DJ: Antidepressant efficacy of highfrequency transcranial magnetic stimulation over the left dorsolateral prefrontal cortex in double-blind sham-controlled de signs: A meta-analysis. Psychol Med 2009; 39:65-75.

14 Holtzheimer PE 3rd, Russo J, Avery DH: A meta-analysis of repetitive transcranial magnetic stimulation in the treatment of depression. Psychopharmacol Bull 2001;35: 149-169.

15 Martin JL, Barbanoj MJ, Schlaepfer TE, Thompson E, Perez V, Kulisevsky J: Repetitive transcranial magnetic stimulation for the treatment of depression. Systematic review and meta-analysis. Br J Psychiatry 2003;182:480-491.

16 Couturier JL: Efficacy of rapid-rate repetitive transcranial magnetic stimulation in the treatment of depression: a systematic review and meta-analysis. J Psychiatry Neurosci 2005;30:83-90.

17 Slotema CW, Blom JD, Hoek HW, Sommer IE: Should we expand the toolbox of psychiatric treatment methods to include repetitive transcranial magnetic stimulation (rTMS)? A meta-analysis of the efficacy of rTMS in psychiatric disorders. J Clin Psychiatry 2010; 71:873-884.

18 Wassermann EM: Risk and safety of repetitive transcranial magnetic stimulation: report and suggested guidelines from the international workshop on the safety of repetitive transcranial magnetic stimulation, June 5-7, 1996. Electroencephalogr Clin Neurophysiol 1998;108:1-16.

19 Rossi S, Hallett M, Rossini PM, Pascual-Leone A: Safety, ethical considerations, and application guidelines for the use of transcranial magnetic stimulation in clinical practice and research. Clin Neurophysiol 2009;120: 2008-2039.

20 Zyss T, Mamczarz J, Vetulani J: The influence of rapid-rate transcranial magnetic stimulation (rTMS) parameters on rTMS effects in porsolt's forced swimming test. Int J Neuropsychopharmacol 1999;2:31-34.

21 Oswald WD, Roth E: Der Zahlen-Verbindungs-Test (ZVT). Göttingen, Hogrefe, 1987.
22 Erzigkeit H: The SKT - a short cognitive performance test as an instrument for the assessment of clinical efficacy of cognition enhancers; in Bergener M, Reisberg B (eds): Diagnosis and Treatment of Senile Dementia. Berlin, Springer, 1989, pp 164-174.

23 Herwig U, Satrapi P, Schonfeldt-Lecuona C: Using the international 10-20 EEG system for positioning of transcranial magnetic stimulation. Brain Topogr 2003;16:95-99.

24 Kasper S, Zivkov M, Roes KC, Pols AG: Pharmacological treatment of severely depressed patients: a meta-analysis comparing efficacy of mirtazapine and amitriptyline. Eur Neuropsychopharmacol 1997;7:115-124.

25 Versiani M, Moreno R, Ramakers-van Moorsel CJ, Schutte AJ: Comparison of the effects of mirtazapine and fluoxetine in severely depressed patients. CNS Drugs 2005; 19:137-146.

26 Eranti S, Mogg A, Pluck G, Landau S, Purvis R, Brown RG, Howard R, Knapp M, Philpot M, Rabe-Hesketh S, Romeo R, Rothwell J, Edwards D, McLoughlin DM: A randomized, controlled trial with 6-month follow-up of repetitive transcranial magnetic stimulation and electroconvulsive therapy for severe depression. Am J Psychiatry 2007;164:73-81.

27 George MS, Post RM: Daily left prefrontal repetitive transcranial magnetic stimulation for acute treatment of medication-resistant depression. Am J Psychiatry 2011;168:356364.

28 Sachdev PS, McBride R, Loo C, Mitchell PM, Malhi GS, Croker V: Effects of different frequencies of transcranial magnetic stimulation (TMS) on the forced swim test model of depression in rats. Biol Psychiatry 2002;51: 474-479.

29 Benninger DH, Lomarev M, Wassermann EM, Lopez G, Houdayer E, Fasano RE, Dang N, Hallett M: Safety study of $50 \mathrm{~Hz}$ repetitive transcranial magnetic stimulation in patients with Parkinson's disease. Clin Neurophysiol 2009;120:809-815.

30 Triggs WJ, Ricciuti N, Ward HE, Cheng J, Bowers D, Goodman WK, Kluger BM, Nadeau SE: Right and left dorsolateral prefrontal rTMS treatment of refractory depression: a randomized, sham-controlled trial. Psychiatry Res 2010;178:467-474.

-31 Brunoni AR, Lopes M, Kaptchuk TJ, Fregni F: Placebo response of non-pharmacological and pharmacological trials in major depression: a systematic review and meta-analysis. PLoS One 2009; 4:e4824.

32 Herwig U, Fallgatter AJ, Hoppner J, Eschweiler GW, Kron M, Hajak G, Padberg F, NaderiHeiden A, Abler B, Eichhammer P, Grossheinrich N, Hay B, Kammer T, Langguth B, Laske C, Plewnia C, Richter MM, Schulz M, Unterecker S, Zinke A, Spitzer M, Schonfeldt-Lecuona C: Antidepressant effects of augmentative transcranial magnetic stimulation: randomised multicentre trial. $\mathrm{Br} \mathrm{J}$ Psychiatry 2007;191:441-448. 
33 Berlim MT, McGirr A, Beaulieu MM, Turecki G: High frequency repetitive transcranial magnetic stimulation as an augmenting strategy in severe treatment-resistant major depression: a prospective 4-week naturalistic trial. J Affect Disord 2010;130:312-317.

\34 Ray S, Nizamie SH, Akhtar S, Praharaj SK, Mishra BR, Zia-ul-Haq M: Efficacy of adjunctive high frequency repetitive transcranial magnetic stimulation of left prefrontal cortex in depression: a randomized sham controlled study. J Affect Disord 2010;128: 153-159.

35 Berlim MT, Turecki G: What is the meaning of treatment resistant/refractory major depression (TRD)? A systematic review of current randomized trials. Eur Neuropsychopharmacol 2007;17:696-707.

36 Kaptchuk TJ, Goldman P, Stone DA, Stason WB: Do medical devices have enhanced placebo effects? J Clin Epidemiol 2000;53:786792.

37 Fava M: Diagnosis and definition of treatment-resistant depression. Biol Psychiatry 2003;53:649-659.

-38 Fitzgerald PB, Benitez J, de Castella A, Daskalakis ZJ, Brown TL, Kulkarni J: A randomized, controlled trial of sequential bilateral repetitive transcranial magnetic stimulation for treatment-resistant depression. Am J Psychiatry 2006;163:88-94.

39 Loo CK, Sachdev PS, Haindl W, Wen W, Mitchell PB, Croker VM, Malhi GS: High (15 $\mathrm{Hz})$ and low $(1 \mathrm{~Hz})$ frequency transcranial magnetic stimulation have different acute effects on regional cerebral blood flow in depressed patients. Psychol Med 2003;33:9971006.
40 Loo CK, Taylor JL, Gandevia SC, McDarmont BN, Mitchell PB, Sachdev PS: Transcranial magnetic stimulation (TMS) in controlled treatment studies: are some 'sham' forms active? Biol Psychiatry 2000;47:325331.

41 Avery DH, Isenberg KE, Sampson SM, Janicak PG, Lisanby SH, Maixner DF, Loo C, Thase ME, Demitrack MA, George MS: Transcranial magnetic stimulation in the acute treatment of major depressive disorder: clinical response in an open-label extension trial. J Clin Psychiatry 2008;69:441-451.

42 Loo CK, Mitchell PB: A review of the efficacy of transcranial magnetic stimulation (TMS) treatment for depression, and current and future strategies to optimize efficacy. J Affect Disord 2005;88:255-267.

43 Mahlberg R, Adli M, Bschor T, Kienast T: Age effects on trail making test during acute depressive and manic episode. Int J Neurosci 2008;118:1347-1356.

44 Ahmed MA, Darwish ES, Khedr EM, El Serogy YM, Ali AM: Effects of low versus high frequencies of repetitive transcranial magnetic stimulation on cognitive function and cortical excitability in Alzheimer's dementia. J Neurol 2012;259:83-92.

45 Pier MP, Hulstijn W, Sabbe BG: No psychomotor slowing in fine motor tasks in dysthymia. J Affect Disord 2004;83:109-120.

46 Neu P, Kiesslinger U, Schlattmann P, Reischies FM: Time-related cognitive deficiency in four different types of depression. Psychiatry Res 2001;103:237-247.
7 Baeken C, De Raedt R, Santermans L, Zeeuws D, Vanderhasselt MA, Meers M, Vanderbruggen N: HF-rTMS treatment decreases psychomotor retardation in medication-resistant melancholic depression. Prog Neuropsychopharmacol Biol Psychiatry 2010;34: 684-687.

48 Padberg F, Zwanzger P, Keck ME, Kathmann N, Mikhaiel P, Ella R, Rupprecht P, Thoma H, Hampel H, Toschi N, Moller HJ: Repetitive transcranial magnetic stimulation (rTMS) in major depression: relation between efficacy and stimulation intensity. Neuropsychopharmacology 2002;27:638645.

49 Huang YZ, Edwards MJ, Rounis E, Bhatia KP, Rothwell JC: Theta burst stimulation of the human motor cortex. Neuron 2005;45: 201-206.

50 Grossheinrich N, Rau A, Pogarell O, HennigFast K, Reinl M, Karch S, Dieler A, Leicht G, Mulert C, Sterr A, Padberg F: Theta burst stimulation of the prefrontal cortex: safety and impact on cognition, mood, and resting electroencephalogram. Biol Psychiatry 2009; 65:778-784.

-51 Chistyakov AV, Rubicsek O, Kaplan B, Zaaroor M, Klein E: Safety, tolerability and preliminary evidence for antidepressant efficacy of theta-burst transcranial magnetic stimulation in patients with major depression. Int J Neuropsychopharmacol 2010;13: 387-393.

52 Holzer M, Padberg F: Intermittent theta burst stimulation (iTBS) ameliorates therapy-resistant depression: a case series. Brain Stimul 2010;3:181-183. 